\title{
Erratum to: Evaluation of the performance of ADMS in predicting the dispersion of sulfur dioxide from a complex source in Southeast Asia: implications for health impact assessments
}

\author{
Michael E. Deary • Somchai Uapipatanakul
}

Published online: 20 August 2014

(C) Springer Science+Business Media Dordrecht 2014

\section{Erratum to: Air Qual Atmos Health}

DOI 10.1007/s11869-013-0225-8

The original version of this article unfortunately contained an error. Tables 4 and 5 should have used bold font to indicate those performance parameters (average for 2003 to 2005) that conformed with the acceptance criteria listed in Table 6. Unfortunately all of the performance parameters are highlighted in bold.

Please refer to the amended Tables 4 and 5 here.

The online version of the original article can be found at http://dx.doi.org/ 10.1007/s11869-013-0225-8.

\section{E. Deary $(\bowtie)$}

Faculty of Engineering and Environment, Northumbria University,

Ellison Building, Newcastle upon Tyne NE1 8ST, UK

e-mail: michael.deary@unn.ac.uk

\section{S. Uapipatanakul}

Kinetics Corporation Ltd, 388 Ratchadapisek Road, Chandrakasem,

Chatuchak, Bangkok 10900, Thailand 


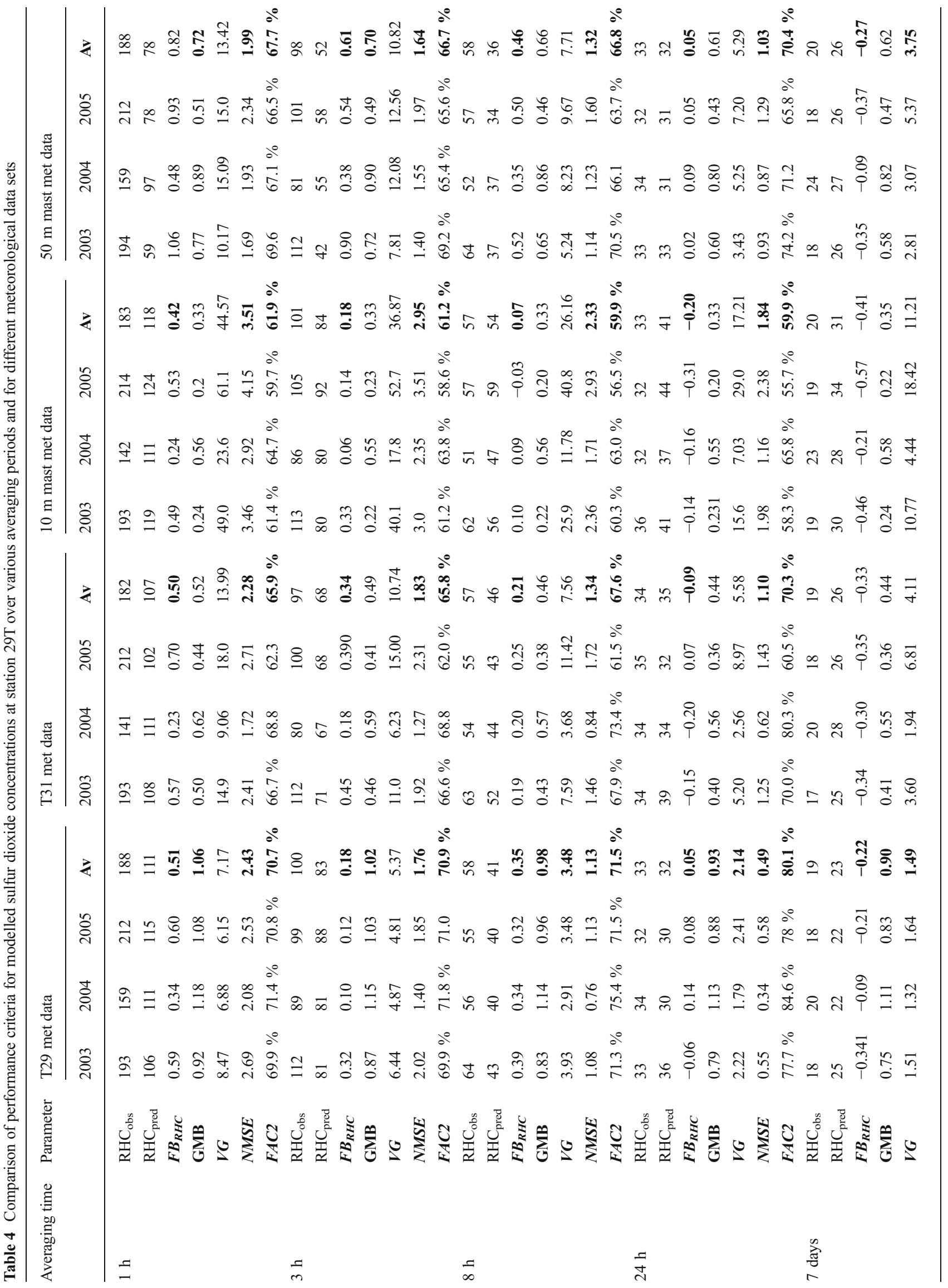




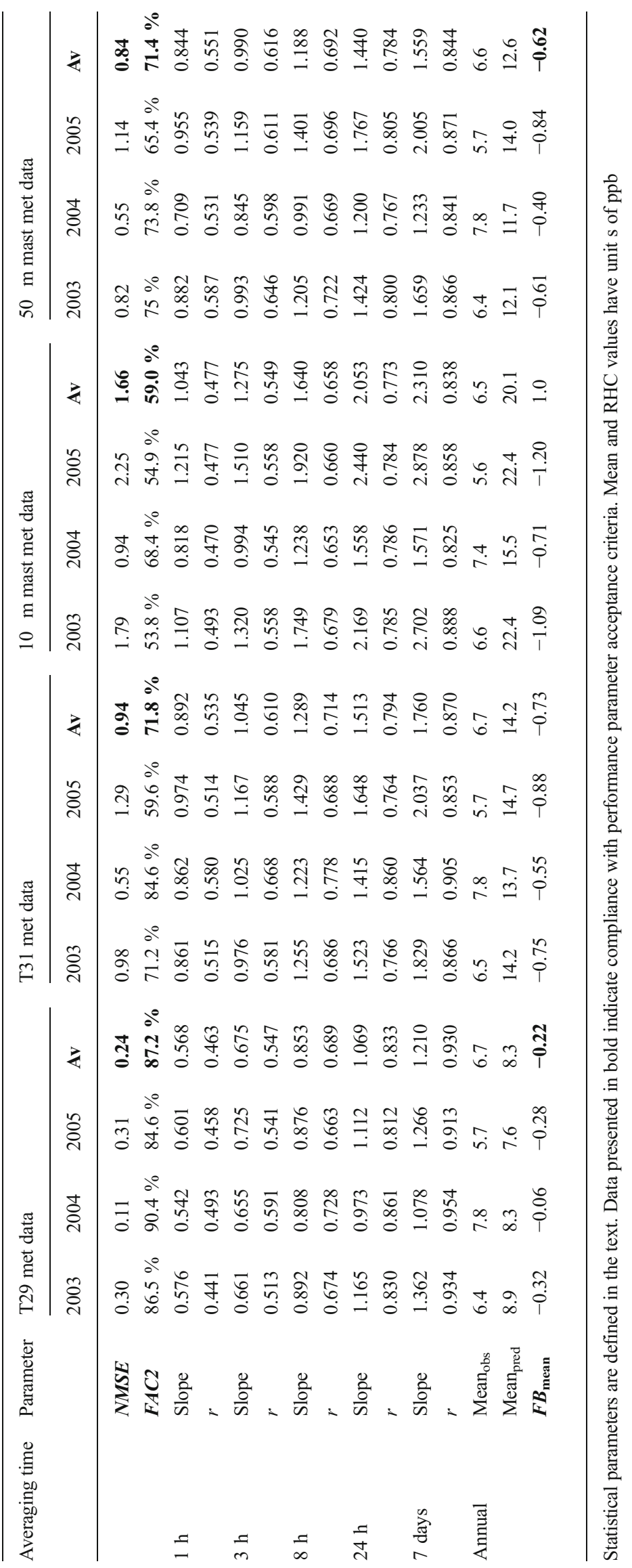




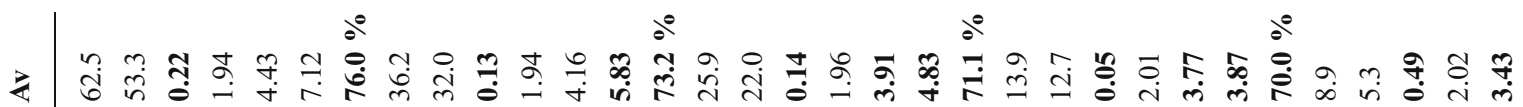

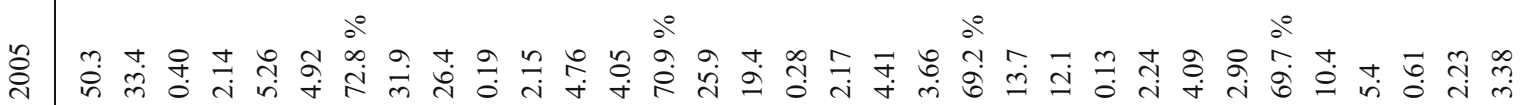

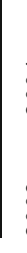

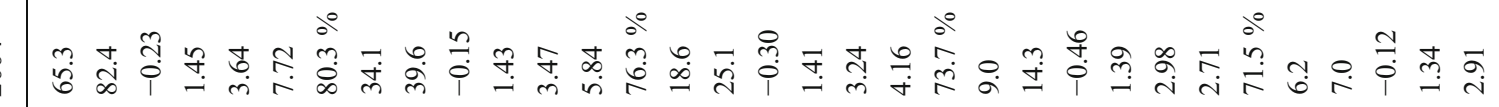

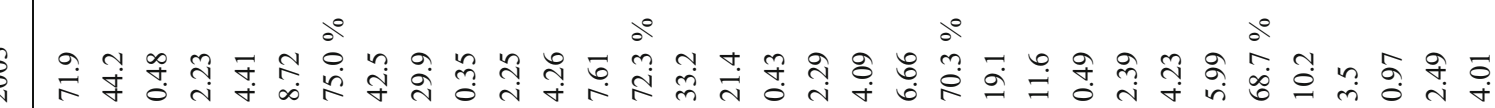

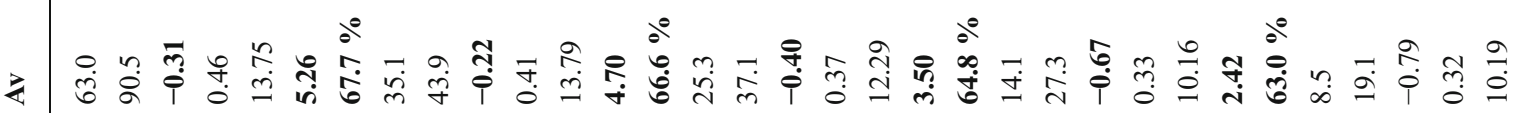

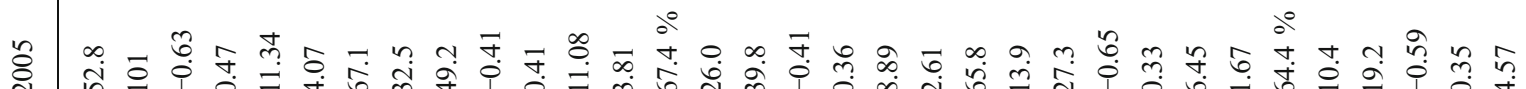

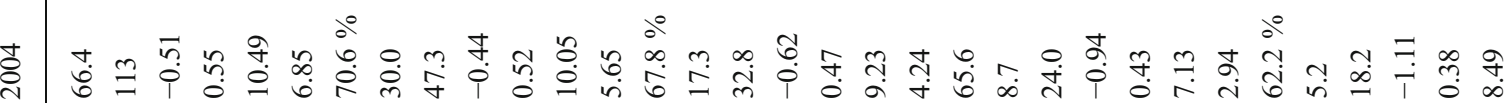

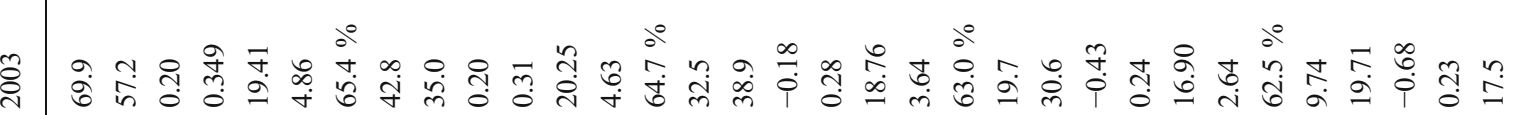

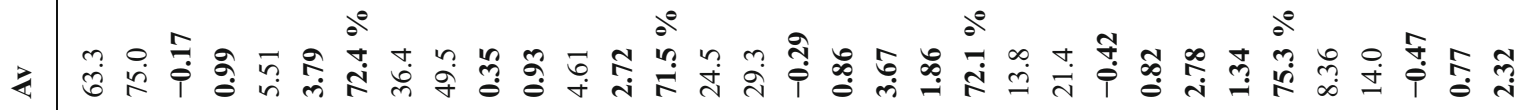
过 Tे do 0 d

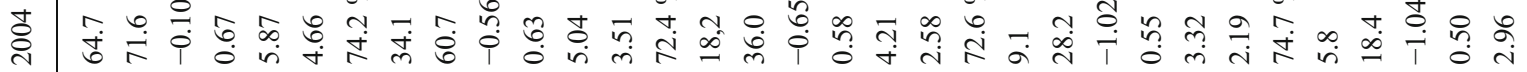
m व

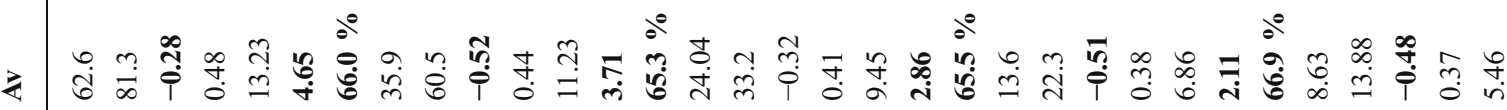

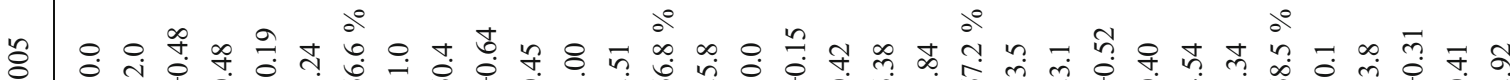
व

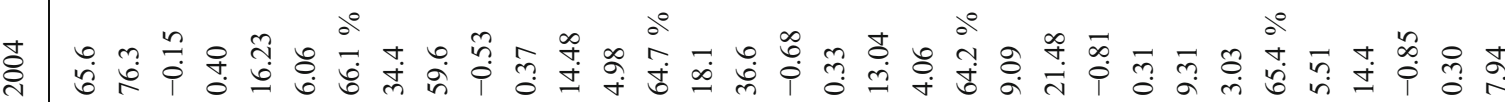

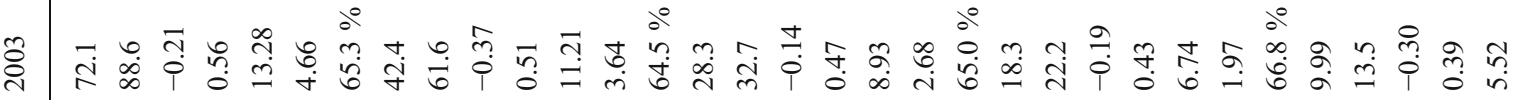

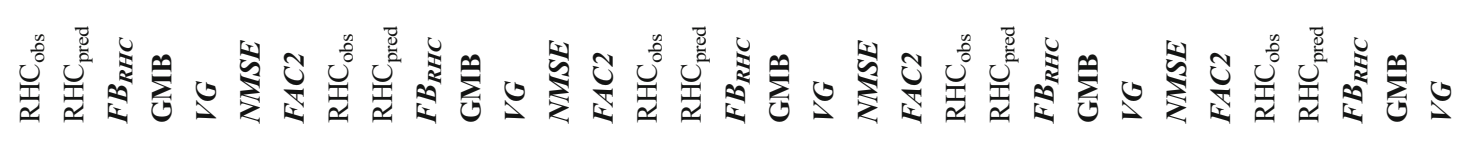




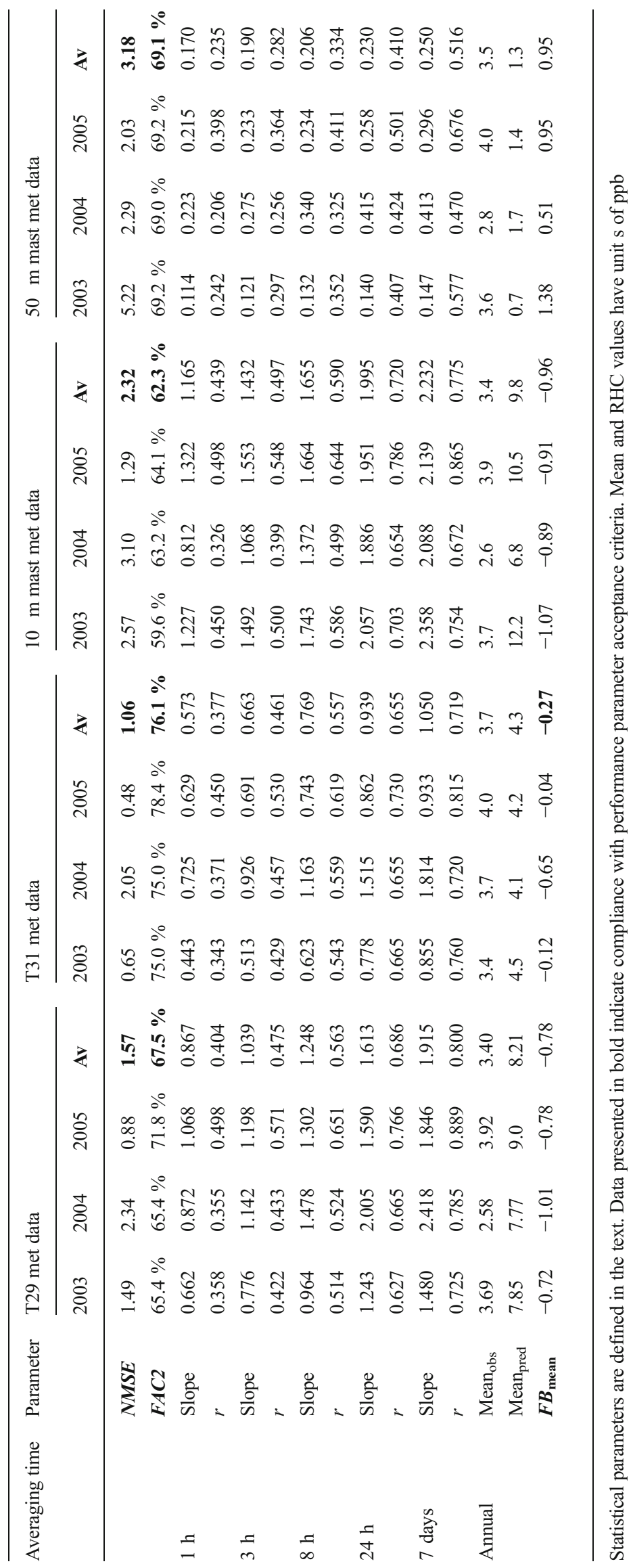

